\title{
Intertidal finger bars at El Puntal, Bay of Santander, Spain: observation and forcing analysis
}

\author{
E. Pellón, R. Garnier, and R. Medina \\ Environmental Hydraulics Institute (IH Cantabria), Universidad de Cantabria, Santander, Spain \\ Correspondence to: E. Pellón (pellone@ unican.es) and R. Garnier (garnierr@ unican.es) \\ Received: 15 October 2013 - Published in Earth Surf. Dynam. Discuss.: 13 November 2013 \\ Revised: 2 May 2014 - Accepted: 11 May 2014 - Published: 26 June 2014
}

\begin{abstract}
A system of 15 small-scale finger bars has been observed, by using video imagery, between 23 June 2008 and 2 June 2010. The bar system is located in the intertidal zone of the swell-protected beaches of El Puntal Spit, in the Bay of Santander (northern coast of Spain). The bars appear on a planar beach (slope $=0.015$ ) with fine, uniform sand $\left(D_{50}=0.27 \mathrm{~mm}\right)$ and extend $600 \mathrm{~m}$ alongshore. The cross-shore span of the bars is determined by the tidal horizontal excursion (between 70 and $130 \mathrm{~m}$ ). They have an oblique orientation with respect to the low-tide shoreline; specifically, they are down-current-oriented with respect to the dominant sand transport computed (mean angle of $26^{\circ}$ from the shore normal). Their mean wavelength is $26 \mathrm{~m}$ and their amplitude varies between 10 and $20 \mathrm{~cm}$. The full system slowly migrates to the east (sand transport direction) with a mean speed of $0.06 \mathrm{~m} \mathrm{day}^{-1}$, a maximum speed in winter (up to $0.15 \mathrm{~m} \mathrm{day}^{-1}$ ) and a minimum speed in summer. An episode of merging has been identified as bars with larger wavelength seem to migrate more slowly than shorter bars. The wind blows predominantly from the west, generating waves that transport sediment across the bars during high-tide periods. This is the main candidate to explain the eastward migration of the system. In particular, the wind can generate waves of up to $20 \mathrm{~cm}$ (root-mean-squared wave height) over a fetch that can reach $4.5 \mathrm{~km}$ at high tide. The astronomical tide seems to be important in the bar dynamics, as the tidal level changes the fetch and also determines the time of exposure of the bars to the surf-zone waves and currents. Furthermore, the river discharge could act as input of suspended sediment in the bar system and play a role in the bar dynamics.
\end{abstract}

\section{Introduction}

Transverse bars are morphological features attached to the shore that appear with a noticeable rhythmicity along the coast of sandy beaches. They have been identified in many types of environments and have been observed with a wide range of characteristics; therefore a classification of the existing bar systems is necessary. This is not straightforward since these features can be classified using many criteria such as their geometry (length scale, orientation with respect to the shoreline), their dynamics (formation time, migration) or their hydro-morphological environment. Alternatively, classification can be made based on the physical processes governing their formation and their dynamics, although these are sometimes not well understood.
The most documented and observed transverse bar type is probably the "TBR" ("transverse bar and rip") described by Wright and Short (1984), which imposes a cuspate shape on the shoreline, sometimes called mega-cusps (Thornton et al., 2007). They sometimes appear with an oblique orientation with respect to the shoreline (Lafon et al., 2002; Castelle et al., 2007). The TBR are typically linked to outer morphological patterns; specifically, they form due to the onshore migration of a crescentic bar (Ranasinghe et al., 2004; Garnier et al., 2008). They are generally found on intermediate wave-dominated beaches of open coasts and they have wavelengths (distance between two bars) of 100-500 $\mathrm{m}$, and are associated with the presence of rip currents flowing offshore between two bars. Remarkably, the study of Goodfellow and Stephenson (2005) shows that these systems can also appear, at smaller scales, in lower-energy environments $(40 \mathrm{~km} \mathrm{li-}$ mited fetch). 
Table 1. Transverse bar types and main characteristics.

\begin{tabular}{|c|c|c|c|c|c|c|c|}
\hline Type & $\begin{array}{l}\text { Beach } \\
\text { type }\end{array}$ & $\begin{array}{l}\text { Mean } \\
\text { wave } \\
\text { height } \\
(\mathrm{m})^{\mathrm{a}}\end{array}$ & $\begin{array}{l}\text { Bar } \\
\text { wave } \\
\text { length } \\
(\mathrm{m})^{\mathrm{a}}\end{array}$ & $\begin{array}{l}\text { Cross-shore } \\
\text { span } \\
(\mathrm{m})^{\mathrm{a}}\end{array}$ & $\begin{array}{l}\text { Bar } \\
\text { orientation }\end{array}$ & $\begin{array}{l}\text { Migration } \\
\text { rate }^{\mathrm{b}} \\
\left(\mathrm{m}_{\text {day }}{ }^{-1}\right)\end{array}$ & $\begin{array}{l}\text { Reference of } \\
\text { observed } \\
\text { bars }\end{array}$ \\
\hline $\begin{array}{l}\text { TBR } \\
\text { (transverse } \\
\text { bars and } \\
\text { rips) }\end{array}$ & $\begin{array}{l}\text { Intermediate } \\
\text { wave-dominated } \\
\text { beaches }\end{array}$ & $>0.5$ & $100-500$ & $<150$ & $\begin{array}{l}\text { Normal, } \\
\text { oblique }\end{array}$ & $5^{c}$ & $\begin{array}{l}\text { Wright and Short (1984) } \\
\text { Lafon et al. (2002) } \\
\text { Ranasinghe et al. (2004) } \\
\text { Goodfellow and Stephenson }(2005)^{\mathrm{d}} \\
\text { Castelle et al. (2007) } \\
\text { Thornton et al. (2007) }\end{array}$ \\
\hline $\begin{array}{l}\text { Large- } \\
\text { scale } \\
\text { finger } \\
\text { bars }\end{array}$ & $\begin{array}{l}\text { Low-energy } \\
\text { beaches, wide } \\
(\sim 1 \mathrm{~km}) \\
\text { with gentle } \\
\text { slope }(0.002)\end{array}$ & $<0.5$ & $\sim 100$ & $\sim 1000$ & $\begin{array}{l}\text { Normal } \\
\text { or } \\
\text { slightly } \\
\text { oblique }\end{array}$ & 1 & $\begin{array}{l}\text { Niederoda and Tanner (1970) } \\
\text { Gelfenbaum and Brooks (2003) } \\
\text { Levoy et al. (2013) }\end{array}$ \\
\hline $\begin{array}{l}\text { Finger } \\
\text { bars of } \\
\text { intermediate } \\
\text { beaches }\end{array}$ & $\begin{array}{l}\text { Intermediate } \\
\text { wave-dominated } \\
\text { beaches }\end{array}$ & $>0.5$ & $50-100$ & $<100$ & $\begin{array}{l}\text { Oblique } \\
\text { up-current- } \\
\text { oriented }\end{array}$ & 40 & $\begin{array}{l}\text { Konicki and Holman (2000) } \\
\text { Ribas and Kroon (2007) } \\
\text { Ribas et al. (2014) }\end{array}$ \\
\hline $\begin{array}{l}\text { Small- } \\
\text { scale } \\
\text { low-energy } \\
\text { finger } \\
\text { bars }\end{array}$ & $\begin{array}{l}\text { Very fetch- } \\
\text { limited } \\
(<10 \mathrm{~km})\end{array}$ & $<0.1$ & $<50$ & $<100$ & $\begin{array}{l}\text { Oblique } \\
\text { down-current- } \\
\text { oriented }\end{array}$ & $\begin{array}{l}\text { Lack } \\
\text { of } \\
\text { data }\end{array}$ & $\begin{array}{l}\text { Falqués (1989) } \\
\text { Bruner and Smosna (1989) } \\
\text { Nordstrom and Jackson (2012) } \\
\text { Present study }\end{array}$ \\
\hline
\end{tabular}

Here we will focus on "(transverse) finger bars", which differ from the TBR because they do not emerge from offshore bathymetric features but are assumed to form "alone". Moreover, they are not necessarily associated with rip currents. Regarding their geometry, the main difference with the TBR is that the finger bars are long-crested, i.e. their crossshore extent is generally larger than their wavelength. We identify three types of finger bars (Table 1).

1. The first type of finger bar was identified by Niedoroda and Tanner (1970). We will refer to them as "largescale finger bars" because of their large cross-shore span ( $\sim 1 \mathrm{~km})$. Their wavelength is $\sim 100 \mathrm{~m}$ and they appear in low-energy environments (mean wave height $<0.5 \mathrm{~m})$ on very wide $(\sim 1 \mathrm{~km})$ beaches with a gentle slope (0.002). They are oriented almost perpendicular to the shore or with a slight obliquity, in both micro- and macro-tidal environments (Gelfenbaum and Brooks, 2003; Levoy et al., 2013).

2. Although finger bars are often associated with very low wave energy (Wijnberg and Kroon, 2002), a second type of finger bar can be observed in intermediate morphological beach states (Konicki and Holman, 2000; Ribas and Kroon, 2007; Ribas et al., 2014). They coexist, at a smaller wavelength (typically $50-100 \mathrm{~m}$ ), with other rhythmic morphologies present in the surf zone, such as with TBR and with crescentic bars. One of the particularities of these "finger bars of intermediate beaches" is that they have an oblique up-current orientation with respect to the mean alongshore current (Ribas et al., 2007).

3. Finally, a third type of finger bar, the "small-scale lowenergy finger bars", appears for very low wave energy in fetch-limited environments (fetch $<10 \mathrm{~km}$ ) with wavelengths of $\sim 10 \mathrm{~m}$ and a cross-shore $\operatorname{span}(10-100 \mathrm{~m})$ that depends on the horizontal tidal excursion (Bruner and Smosna, 1989; Garnier et al., 2012). These bars are not strictly normal to the shore (Falqués, 1989; Nordstrom and Jackson, 2012) but seem to be down-currentoriented with respect to the dominant sand transport (Bruner and Smosna, 1989), which is opposite to the finger bars of intermediate beaches.

The processes of generation and evolution of finger bars are probably different depending on their type, and, in particular, their orientation. It is thought that finger bars generally 
migrate in the direction of sediment transport, but transport direction is not always identified, possibly due to the lack of field data. The theoretical modelling studies of Ribas et al. (2003) and Garnier et al. (2006) have shown different mechanisms to explain the dynamics of up- and downcurrent-oriented bars by considering forcing due to waves. Ribas et al. (2012) successfully applied their model to finger bars of an intermediate beach, based on continuous observations obtained from video imagery. However, the dynamics of finger bars appearing in low-energy environments is poorly understood, especially concerning the small-scale low-energy finger bars because (1) the forcing is difficult to determine, with forces due to wind, waves and tidal currents all similar in magnitude in very limited fetch environments, and (2) there has been no continuous, long-term survey of such systems. Some observation studies on largescale finger bars have measured mean migration rates of less than $2 \mathrm{~m} \mathrm{month}^{-1}$ (Gelfenbaum and Brooks, 2003; Levoy et al., 2013) and maximum speeds of $1 \mathrm{~m} \mathrm{day}^{-1}$ (Levoy et al., 2013). For the case of small-scale low-energy finger bars, only the preliminary study of Garnier et al. (2012) has given information on the dynamics of such systems, but the migration rates detected are overestimated due to strong noise in the data.

The objective of this contribution is to gain insight into the dynamics of small-scale low-energy transverse bars by performing a continuous survey of finger bars detected in the Bay of Santander, Spain, and by analysing the possible forcing mechanisms. These finger bars are located in the intertidal zone, and the survey is performed by using video images at low tide. Section 2 presents the field site and the data set obtained by video imagery. Section 3 describes the characteristics and the dynamics of the bar system. Section 4 reports the forcing analysis based essentially on wind data. The conclusions are listed in Sect. 5.

\section{Field site and video imagery}

\subsection{Study site}

El Puntal Spit is part of the natural closure of the Bay of Santander (Fig. 1). This bay is one of the largest estuaries on the northern coast of Spain (Cantabrian Sea). The closure of the bay is composed of two natural formations, the Magdalena Peninsula to the north-west, and El Puntal Spit to the northeast. This spit is a sand accumulation which extends from east to west over approximately $2.5 \mathrm{~km}$. Historically, more than $50 \%$ of the surface of this bay has been filled in, reducing the tidal prism and changing the morphological equilibrium of El Puntal (Losada et al., 1991), which tends to extend westward. However, for navigation purposes (Medina et al., 2007), the entrance channel is periodically dredged, and thus the west end of El Puntal is maintained artificially.

There are numerous studies on El Puntal analysing the morphodynamics of the northern face and the west end
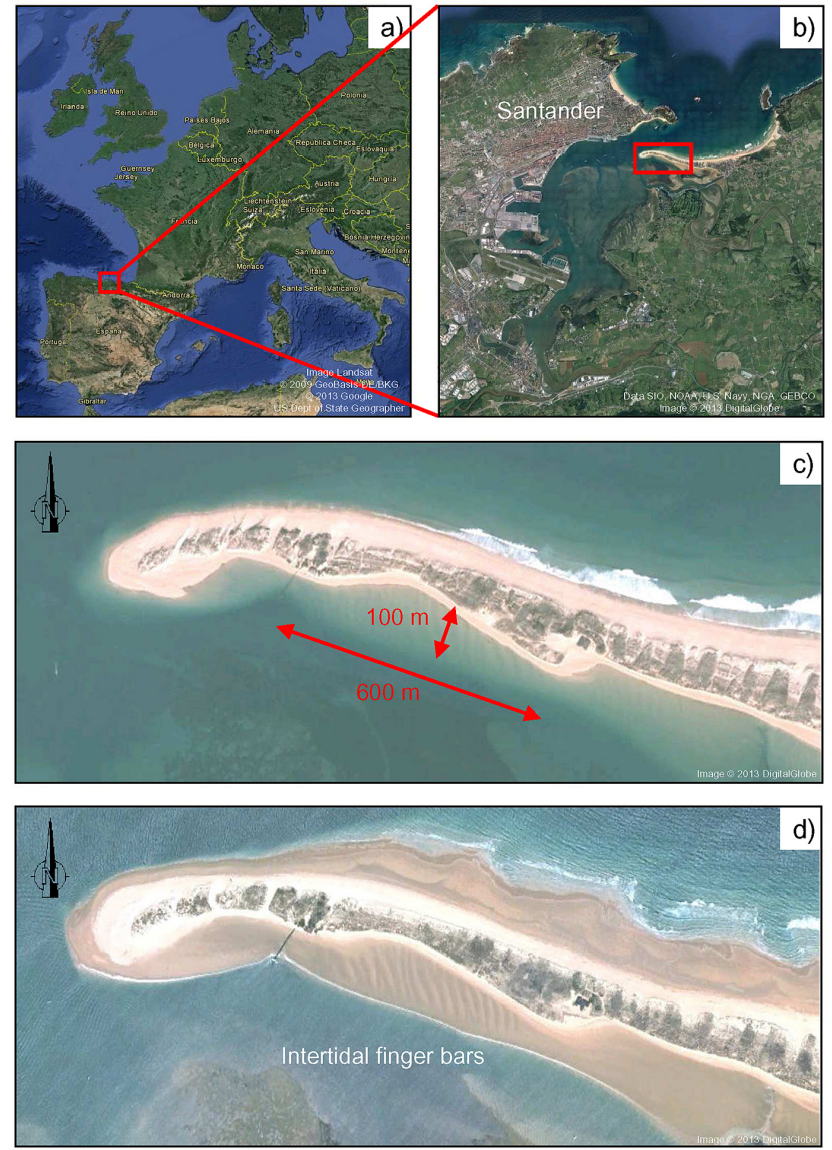

Figure 1. (a) Location of Santander, (b) map of the bay, (c) El Puntal at high tide, and (d) El Puntal at low tide. Images from Google Earth; Landsat; ${ }^{\circledR} 2009$ GeoBasis-DE/BKG; ${ }^{\circledR} 2013$ Google; US Dept of State Geographer; Data SIO, NOAA, U.S. Navy, NGA, GEBCO; ${ }^{\circledR} 2013$ DigitalGlobe.

(Losada et al., 1992; Kroon et al., 2007; Requejo et al., 2008; Medellín et al., 2008, 2009; Gutiérrez et al., 2011), but the lower-energy southern face remains unstudied. The incoming swell from the Cantabrian Sea only reaches the northern face of the spit (Medellín et al., 2008). The southern protected beaches of El Puntal are part of the bay and are located in a low-energy mesotidal environment. The maximum range of the semidiurnal tide is $5 \mathrm{~m}$. Recent hydrodynamic studies (Bidegain et al., 2013) have reported an ebb-oriented mean annual flow of up to $0.1 \mathrm{~m} \mathrm{~s}^{-1}$ in the channel to the south of El Puntal. This flow is mainly driven by the (ebb-dominated) tidal current and by the flow from the Miera River, which enters the bay at the east end of the El Puntal Spit. In the shallower areas the mean flow is much weaker and wind effects can become predominant (Bidegain et al., 2013), especially if we take into account the waves that can be generated over a fetch of up to $4.5 \mathrm{~km}$ from the south-west direction. The fetch is highly variable over a tidal cycle due to the numerous 
intertidal shoals in the bay (Fig. 1b), which can reduce the maximum fetch to $200 \mathrm{~m}$ at low tide.

The finger bar system is located in the intertidal zone of the beach on the southern side of the spit. Aerial images show a system of 15 well-developed finger bars that is fully submerged at high tide (Fig. 1c) and fully emerged at low tide (Figs. 1d and 2a). At mid-tide the coastline exhibits a cuspate shape (Fig. 2) and processes of wave refraction and wave breaking are observed (Fig. 2c).

The alongshore extent of the bar system is less than $600 \mathrm{~m}$ and the mean bar wavelength is about $25 \mathrm{~m}$. The cross-shore extent of the bars is controlled by the horizontal tidal excursion and is larger in the middle of the domain $(130 \mathrm{~m})$ than on the lateral sides $(70 \mathrm{~m})$. The bars are almost parallel and have an oblique orientation with respect to the low-tide coastline. The bar angle with respect to the low-tide shore normal is about $25^{\circ}$ toward the southeast (where $0^{\circ}$ would correspond to shore normal, transverse bars). However, the western end of the system is more irregular, with slight changes in bar orientation and bifurcations (Fig. 1d).

The intertidal beach where the bars appear is planar with a constant slope of approximately 0.015. The offshore boundary of the bars is delimited by a steep slope that ends in the subtidal channel. Sediment sampling has shown the same grain size on bars and troughs with $D_{50}=0.27 \mathrm{~mm}$.

\subsection{Video imagery and bar detection}

In the last few decades, video monitoring systems have been increasingly used to study the shoreline around the world (Holman et al., 1993). To obtain geometric data of the bar system, the images of the Horus video imagery system were used (Medina et al., 2007). This system is composed of four cameras located on the roof of Hotel Real, $91 \mathrm{~m}$ a.s.l. and $1.5 \mathrm{~km}$ from the study area (Fig. 3a). The Horus station was established in 2008 and takes images every $10 \mathrm{~min}$. In the present study only camera 2 was used (Fig. 3b). The pixel resolution on the study area is variable on the alongshore direction, with values from 4.5 to $6.6 \mathrm{~m} \mathrm{pixel}^{-1}$. In the cross-shore direction the resolution is around $0.5 \mathrm{~m} \mathrm{pixel}^{-1}$. One daily image of the bar system has been selected at low tide between 23 June 2008 and 2 June 2010, which is the longest period found without long interruptions in the image database. All the interruptions were of less than 6 consecutive days and were due to technical problems (27 days) and poor meteorological conditions (fog 18 days, strong wind 3 days and bad sharpness 85 days). The geometry of the bars was extracted on 577 days, which is $81 \%$ of the time.

Each bar has been digitised manually by selecting three points along the trough at the upper, middle and lowest end of each bar (Fig. 4). Three points were found to describe the position and orientation sufficiently. These digitised data were rectified using seven geographic control points (GCP), established for the Horus system, thus giving geographic coordinates of each digitised bar.
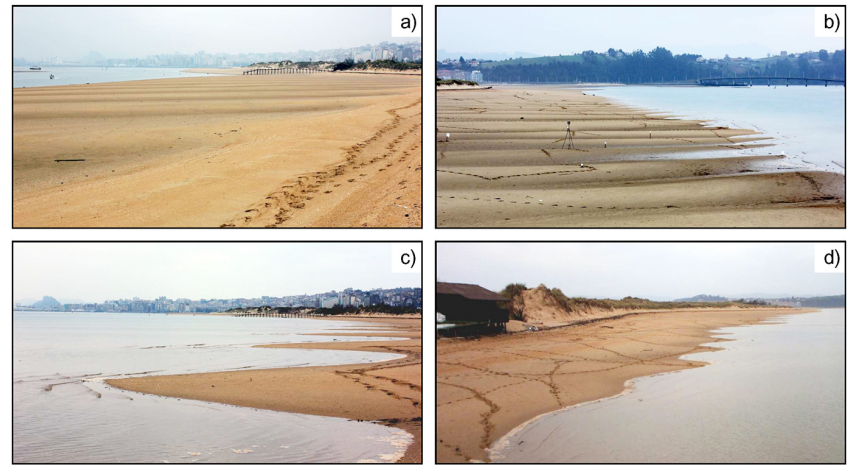

Figure 2. Photos at $(\mathbf{a}, \mathbf{b})$ low tide and with $(\mathbf{c}, \mathbf{d})$ rising tide. Pictures taken from the east end of the study area $(\mathbf{a}, \mathbf{c})$, and from the west end (b, d). Capture date: 25 February 2012.
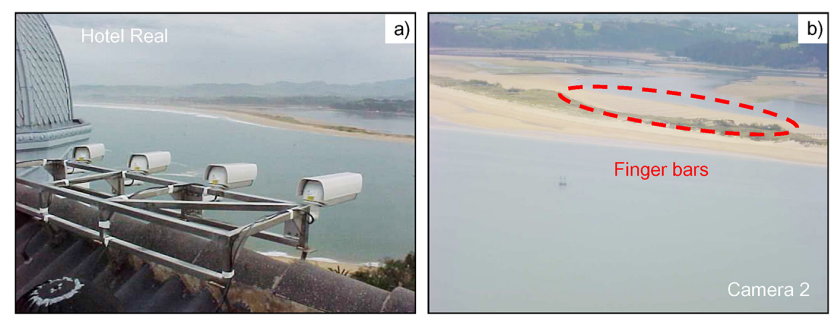

Figure 3. Horus video system. (a) Cameras on the roof of Hotel Real. (b) Image taken by camera 2.

The data processed by Garnier et al. (2012) have been reanalysed in order to correct an apparent periodic movement due to sun shadows in the bars. The amplitude of this periodic movement is of the order of the pixel resolution, and it has been found that its period is related to the capture times. This apparent movement seems to be a systematic error linked to the different sun positions at low tide during the fortnightly cycle of neap-spring tides, which causes different shadows due to the bars and different light reflections in the wet areas. This light shadowing/reflection also occurs for fixed structures present in the surrounding areas. This allowed us to partially correct this spurious movement.

For further analysis, a local, approximately shore-parallel coordinate system has been defined with the alongshore, $y$ axis at $113^{\circ}$ from north (Fig. 4). Within the new coordinate system, the mean shoreline position now is approximately parallel to the $y$ axis during most of the tidal cycle. To better understand the behaviour of the finger bars, the digitised bars are then subsampled at $x 1=45, x 2=65, x 3=85$, and $x 4=105 \mathrm{~m}$ over the length of the alongshore domain $(y 1-$ y4 axes; see Fig. 4). These positions have been chosen to give complete cross-shore coverage of the bars, and each one is representative of one level of the beach profile (Fig. 5c). 


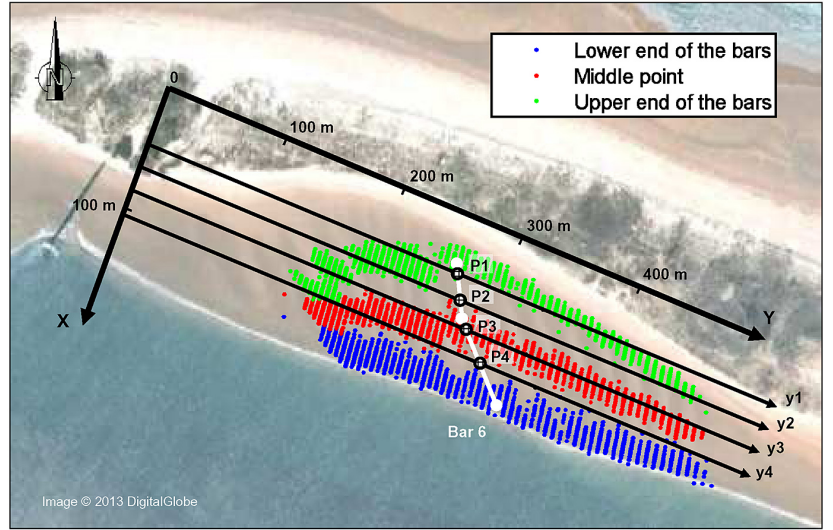

Figure 4. Coordinate system and bar digitisation. The $x$ and $y$ axes stand for the cross-shore and the alongshore direction respectively. The colour points represent the digitised data (each bar is represented by three points); blue, red and green are the lowest, the middle and the upper points of the bars respectively. The bar positions (P1-P4) are defined along the $y 1-y 4$ axes, at $x 1=45, x 2=65$, $x 3=85$, and $x 4=105 \mathrm{~m}$ respectively (see positions of bar 6 , in white). Image from Google Earth, ${ }^{\circledR} 2013$ DigitalGlobe.

\subsection{3-D geometry}

The Horus system captures one image of the study area every $10 \mathrm{~min}$. This means that the path of the shoreline can be observed along the tidal cycle with high frequency. To extract information about the 3-D geometry of the finger bar system, a reconstruction of the intertidal bathymetry of the study area has been performed by mapping the shoreline from every image. This must be done on a day with perfect conditions, as the meteorological conditions and image sharpness need to be excellent. Furthermore, the tide should have the highest range possible, allowing the extraction of a large intertidal region, and this must occur during daylight hours.

On good days, the shoreline is digitised and rectified on each image. To obtain the bathymetry we assume that the sea level measured at the tide gauge of Santander (less than $2 \mathrm{~km}$ away) is the same as the level of the shoreline in the study area. The tide level (with respect to the local Santander Harbour datum, $Z$ ) at the time of each image is associated with the rectified shoreline from that image, obtaining an intertidal bathymetry.

\subsection{Piecewise regression of the bar movement}

The method proposed here to find the time-dependent migration rates is based on piecewise regressions. This allows us to focus on the medium-term movements rather than on the daily fluctuations. The time series of the bar position for each bar at each cross-shore position has been decomposed into segments of variable length. The segment length has been set in order to minimise the error between the piecewise segment and the measured positions. After this decomposition, each bar is represented by several segments of different lengths (the segment $k$ has a length of $T_{k}$ ). For each segment, we can therefore obtain the approximate bar migration rate $V_{k}$, which is the migration rate of this bar during the time interval $T_{k}$.

Considering that, at a time $t, N$ segments are obtained (where $N$ is the number of bars of the system at this time $t$, multiplied by 4 , which is the number of cross-shore positions studied), the time-dependent migration rate of the bar system $V_{\mathrm{m}}$ (which is the average of the speeds, at this time $t$, of all the bars on all the cross-shore positions) is computed as

$V_{\mathrm{m}}(t)=\sum_{i=1}^{N(t)} \frac{\hat{V}_{i}(t)}{N(t)}$, where $\hat{V}_{i}(t)= \begin{cases}V_{\mathrm{k}}, & \text { if } t \in T_{\mathrm{k}} \\ 0, & \text { otherwise }\end{cases}$

\section{Bar characteristics and dynamics}

\subsection{Bathymetry reconstruction}

A bathymetry reconstruction has been done on 12 days with excellent meteorological conditions. Figure 5a shows the bathymetry obtained for 24 June 2008, the day with the best image quality. Cross-shore profiles of this bathymetry (Fig. 5c) show that the bars only appear on the region of the intertidal beach profile which has constant slope of 0.015 . The extraction of alongshore profiles from these bathymetries allows us to measure the amplitude of the bars, which oscillates between 10 and $20 \mathrm{~cm}$. These profiles also show the asymmetry of the bars (Fig. 5b) with steeper slopes on the lee sides (relative to the migration direction), in agreement with previous studies (Gelfenbaum and Brooks, 2003).

\subsection{Bar dynamics}

During the 2-year study period the position and geometry of 15 bars were digitised daily. Figure 6 shows the position of the bar system along the $y 3$ axis once the digitised data have been corrected, rectified and transformed to the described coordinate system (Fig. 4). Taking into account that the pixel resolution on the study area is of about $5 \mathrm{~m} \mathrm{pixel}^{-1}$ in the alongshore direction, the small oscillations visible in Fig. 6 are not deeply analysed, as they could be either physical or measurement errors. The bar system is persistent in time, appearing in all the observed images with similar geometric characteristics, but the entire system slowly migrates to the east. As a result of the eastward migration a new bar becomes visible at the western end of the study area (bar 1, Fig. 6). Although aerial images and the migration of the system suggest that the bars are formed at the west of the study area, the formation area is not included in the present results as it is hidden by the dune (Fig. 5a). At the eastern end of the area, the last bar decays and slowly disappears. In addition, during the study period, only one episode of merging of two bars into one has been detected, on 28 March 2009 (bars 5-6, Fig. 6). 

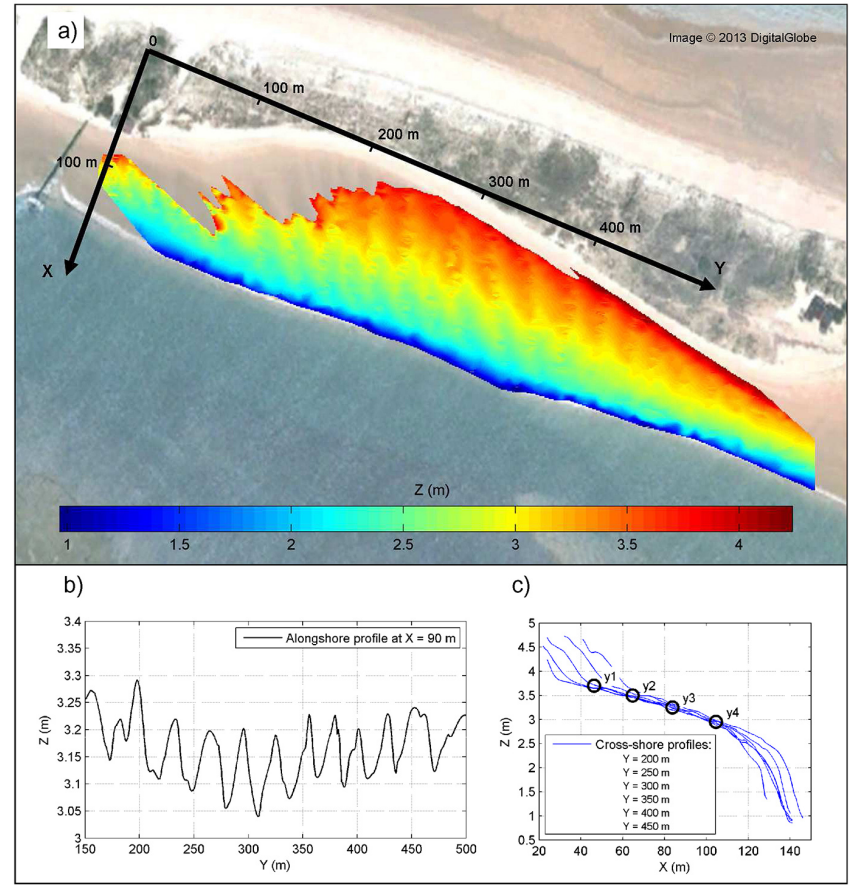

Figure 5. (a) Bathymetry reconstruction with videoed shoreline positions during rising tide (24 June 2008). The north-west area without data is the shadowed area by the dune, from the point of view of the camera. (b) Alongshore profile of the bed level. (c) Cross-shore profiles of the bed level and cross-shore positions of the $y 1-y 4$ axes. Image from Google Earth, ${ }^{\circledR} 2013$ DigitalGlobe.

\subsubsection{Time-averaged characteristics}

The digitised and rectified data allow the daily measurement of the bar wavelength. The bar wavelength is computed as the difference between the positions (on the $y_{i}$ axis) of two consecutive troughs. For each bar, the wavelength has been averaged over the complete study period (Fig. 7). The wavelength is approximately constant for each bar during the study period (standard deviation, $\sigma$, around $4 \mathrm{~m}$ for all bars), but varies between bars, with a minimum of $15 \mathrm{~m}$ and a maximum of $36 \mathrm{~m}$. The mean wavelength of the whole bar system is $25.8 \mathrm{~m}$.

Similarly, the variability of the mean bar angle is low, with $\sigma$ around $5^{\circ}$ for each bar. The mean angle of the system, measured from the $x$ axis, is $26.4^{\circ}$, with a maximum angle of $34^{\circ}$ at the western end, decreasing to a minimum of $17^{\circ}$ at the eastern end (Fig. 7). The bars are not straight in plan view, so their angle has also been studied by splitting the bars into two parts, the upper (onshore) half and the lower (offshore) half. The upper part of all the bars has a lower angle with the shore normal (mean of the whole system of $23^{\circ}$ ), while the lower part has higher angles (mean of $31^{\circ}$ ).

The time series of bar position is almost continuous and allows us to compute the time-averaged migration rate of the system, which is obtained by linear regression. The mean

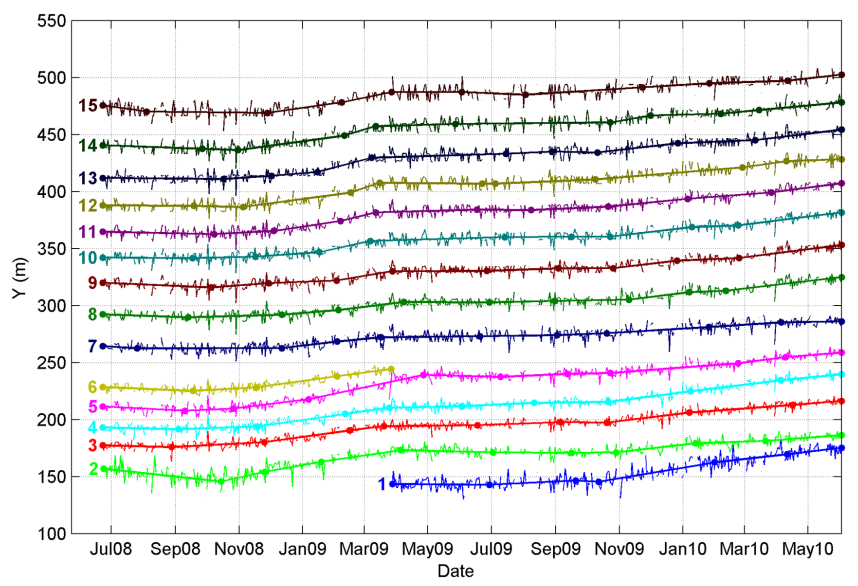

Figure 6. Evolution of the bar system. Time series of the bar position along the $y 3$ axis. The thin, discontinuous lines represent the measured position. The thick segments represent the piecewise regression of the measured position. The number to the left of each line indicates the bar number.

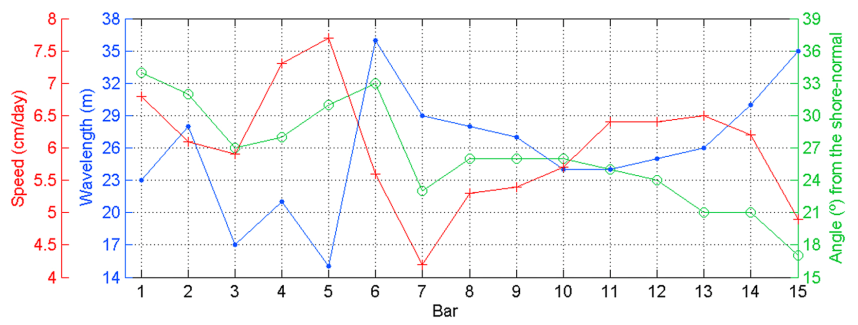

Figure 7. Time-averaged wavelength, angle and migration rate of each bar. The bar angles are measured from the shore normal to the east. Positive values of the bar speeds represent movements of the bars to the east.

speed of each bar (for the whole study period) is shown in Fig. 7. All the bars of the system slowly migrate to the east, with a mean speed of $6 \mathrm{~cm} \mathrm{day}^{-1}$ (approximately one wavelength per year). The maximum migration rate is obtained for the bar with the shortest wavelength $\left(8 \mathrm{~cm} \mathrm{day}^{-1}\right.$, bar 5) that merges with the next bar, which is longer and slower (bar 6). In general, the longer the wavelength, the slower the migration rate. This is in agreement with previous studies on transverse bars (Garnier et al., 2006).

There are noticeable differences in the dynamics and in the characteristics of the first five bars (western bars) compared with the eastern bars. The western bars (close to the formation zone) are more irregular in shape, with a larger mean angle ( $5^{\circ}$ larger), a smaller wavelength $(20 \mathrm{~m}$ mean) and a corresponding higher migration rate. The eastern bars are well defined and remarkably parallel. Their cross-shore span decreases as they approach the decaying zone. 


\subsubsection{Time-dependent migration rates}

Each bar signal has been decomposed into 10 segments by means of the piecewise regression described in Sect. 2.4 (Fig. 6). It was found that 10 is the best number to represent the medium-term movement of the bar and to filter the daily fluctuations. As we are analysing 2 years of data, the mean segment length is 70 days.

The migration rate of the bar system $V_{\mathrm{m}}$, computed with (Eq. 1), is not constant in time with maximum migration rates in winter (Fig. 8). The maximum speeds, about $0.15 \mathrm{~m} \mathrm{day}^{-1}$, are reached during the first winter studied (2009), while during the second winter (2010) the maximum speeds are lower than $0.1 \mathrm{~m} \mathrm{day}^{-1}$. During summer the system migration is slower, with negative speeds for summer 2008, and migration rates lower than $0.01 \mathrm{~m} \mathrm{day}^{-1}$ for summer 2009. The negative speeds (i.e. migration to the west) found in summer 2008 can be due to limitations in the computation of $V_{\mathrm{m}}$. Specifically, the accuracy of the piecewise regression is expected to be lower at the beginning and end of the time series, due to the lack of previous/subsequent data. The negative migration rate is obtained for the first segment of the bars only; therefore this result may not be realistic.

\section{Forcing analysis}

\subsection{Forcing candidates}

The migration to the east of the bar system indicates a dominant forcing coming from the west. The wind data have been extracted from the SeaWind (Menéndez et al., 2011) reanalysis database. Figure $9 \mathrm{a}$ shows the wind rose, and the time series of the wind speed is displayed in Fig. 9c. The predominant wind is from the west, reaching values of up to $25 \mathrm{~m} \mathrm{~s}^{-1}$. The wind from the east is also frequent but less energetic, with speeds lower than $15 \mathrm{~m} \mathrm{~s}^{-1}$. The mean wind speed is $5 \mathrm{~m} \mathrm{~s}^{-1}$.

Other studies on transverse bars (Ribas et al., 2003) suggest that waves are the main forcing that controls their dynamics. The study area is protected from the incoming swell (Medellín et al., 2008) and the waves that can act on the bar system are generated locally. According to estuarine studies these wind waves can have a significant effect in the sediment transport (Green et al., 1997). Here, wind waves are generated over a maximum fetch of $4.5 \mathrm{~km}$ (from the south-west of the study area). Toward the south and south-east the fetch is reduced by the proximity of land.

During the survey period, the tidal range oscillates between 1 and $5 \mathrm{~m}$ (Fig. 9d). Maximum values of the tidal current in the channel (offshore of the bar system) occur during spring tides, with values of up to $0.25 \mathrm{~m} \mathrm{~s}^{-1}$. In the channel the mean (residual) flow is ebb-oriented, but the residual tidal current is small in the intertidal areas. Computations performed (not shown) with an H2D model (Bárcena et al., 2012) show that the maximum residual current (obtained dur-
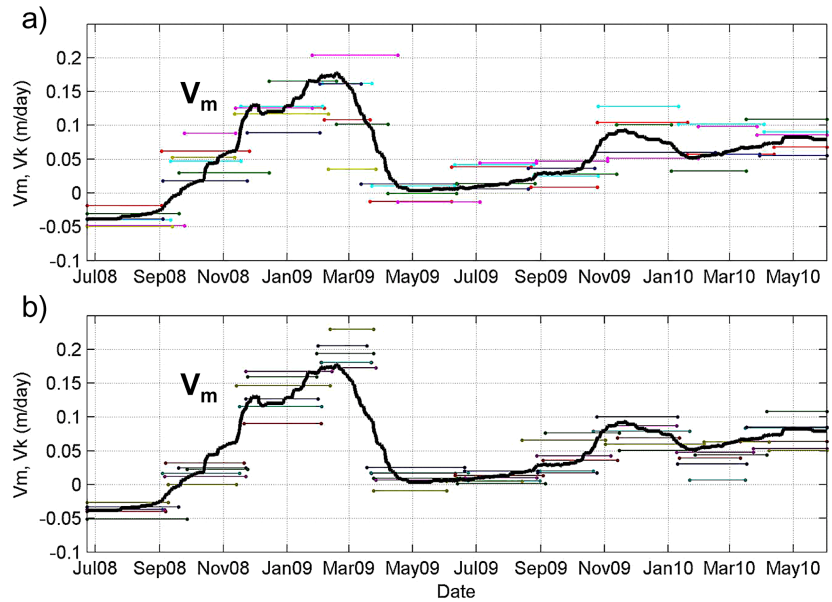

Figure 8. $V_{\mathrm{m}}$ (thick black line), time-dependent migration rate of the entire bar system (average of all coloured lines). $V_{k}$ (colour lines), individual bar migration rate (the colours correspond to Fig. 6). (a) $V_{k}$ for bars 3-8. (b) $V_{k}$ for bars 9-14.
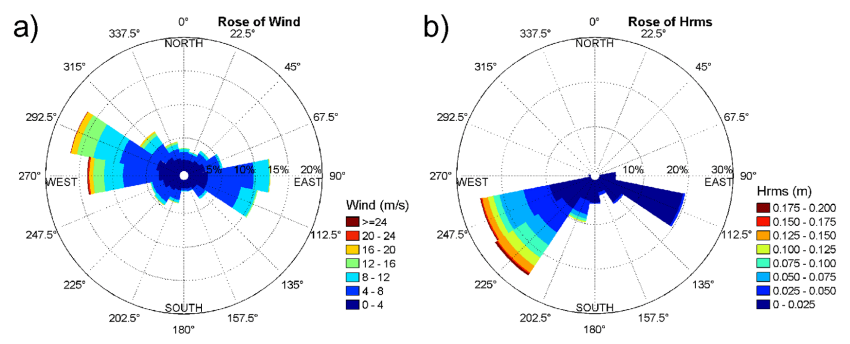

c)

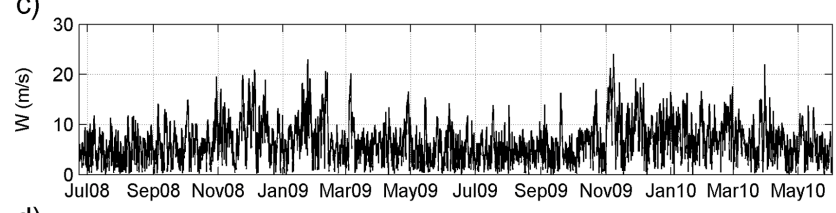

d)

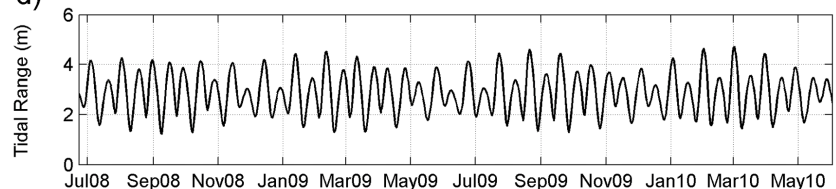

e)
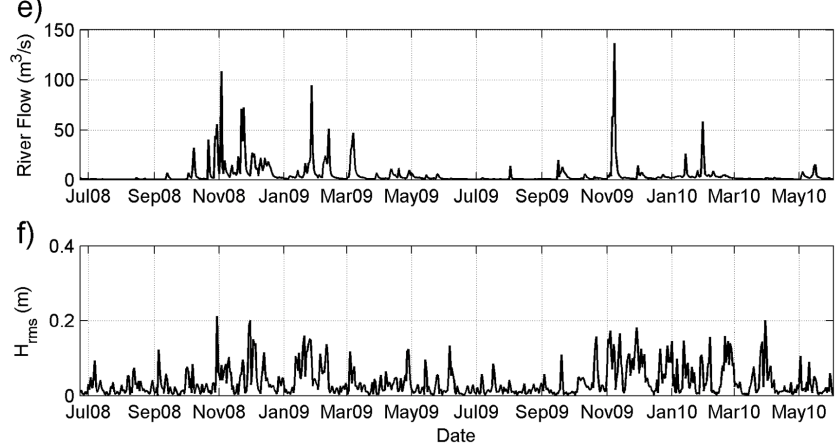

Figure 9. (a) Wind rose. (b) Wave rose. (c-f) Time series of the (c) wind speed $W$, and the daily averaged (d) tidal range, (e) river flow rate and (f) root-mean-squared wave height of the wind waves $H_{\text {rms }}$. 
ing spring tides) is lower than $0.01 \mathrm{~m} \mathrm{~s}^{-1}$ in the study area. Although the residual current is small, the tide can have an effect on the bar dynamics because tidal currents can cause sediment stirring (which is stronger during mid tides) and because of the changes in water level. Firstly, the fetch is strongly dependent on the water level (Green et al., 1997) according to the emersion and submersion of the numerous intertidal shoals during the tidal cycle, and this is taken into account in the wave computations (see Sect. 4.2.1). Secondly, the changes in tidal level affect the time of bar submersion (that is larger during neap tides) and the volume of sand that can be transported (larger if high tide coincides with strong winds/waves). This will be taken into account in the sediment transport computations by including the tidal correction factor (see further explanations in Sect. 4.3.2).

Hydrodynamic studies of the Santander Bay have highlighted the effect of the water discharge produced by the Miera River (to the east of the study area) in the annual mean current magnitude in the bay (Bidegain et al., 2013). Time series of the daily averaged river flow rate are shown in Fig. 9e. Bidegain et al. (2013) have shown that, although the effect of the river is strong in the channel (ebb-oriented flow), the current produced close to the bar system is weak. However, the river discharge can play a role in the bar dynamics as it is linked to a strong sediment supply, which can act as an input of suspended sediment to the bar system.

\subsection{Wind acting on water surface}

\subsubsection{Wave computation}

The wind waves over the system have been simulated from the wind speed and direction by using the SWAN model (Booij et al., 1999). In the computations, changes in tidal level affecting the fetch have been included. The time series of the wind waves has been obtained with an interpolation technique based on radial basis functions (RBF), a scheme which is convenient for scattered and multivariate data (Camus et al., 2011). Results of the root-mean-squared (rms) wave height $H_{\text {rms }}$ of the waves approaching the bar system are displayed in Fig. 9b (wave rose) and in Fig. 9f (time series of the daily averaged $H_{\mathrm{rms}}$ ). The waves arrive from the west-south-west and south-west $65 \%$ of the time, with a mean $H_{\mathrm{rms}}$ of $5 \mathrm{~cm}$ and a period of $1.5 \mathrm{~s}$. During the westward windstorms the waves can extend to $20 \mathrm{~cm}$ from the westsouth-west, with a period of $3 \mathrm{~s}$. The other $35 \%$ of the time the waves come from the east-south-east, with $H_{\mathrm{rms}}$ lower than $7 \mathrm{~cm}$ and periods below $1.7 \mathrm{~s}$. The mean $H_{\text {rms }}$ from this sector is less than $2 \mathrm{~cm}$ with a period of $1.2 \mathrm{~s}$.

\subsubsection{Wind stress vs wind-wave stress forcing}

The previous studies on transverse bars, where the waves appear to be the main forcing, usually focus on wave parameters to relate the dynamics of the bars with the incident wave forcing, for example the alongshore component of the wave energy flux (e.g. Castelle et al., 2007; Price and Ruessink, 2011) or the wave radiation stress (e.g. Ribas and Kroon, 2007).

Here, the effect of the local wind is also analysed by computing the alongshore component of the wind shear stress acting on the water surface (Figs. 10a and 11a), defined as (Dean and Dalrymple, 1991)

$T_{y}=-\rho C_{\mathrm{f}} W^{2} \cos \theta_{\mathrm{w}}$,

where $\rho$ is the water density $\left(\rho=1025 \mathrm{~kg} \mathrm{~m}^{-3}\right)$; $C_{\mathrm{f}}$ is the friction coefficient, equal to $1.2 \times 10^{-6} ; \mathrm{W}$ is the wind speed; and $\theta_{\mathrm{w}}$ is the incoming wind angle (from the shore normal).

In order to compare the relative effect of the wind stress and of the wave radiation stress, we define the alongshore wave stress, $S_{y}=S_{x y} / X_{\mathrm{b}}$ (Figs. $10 \mathrm{~b}$ and $11 \mathrm{~b}$ ). $S_{x y}$ is the alongshore component of the wave radiation stress (LonguetHiggins and Stewart, 1964) and $X_{\mathrm{b}}$ is the surf-zone width. By considering $X_{\mathrm{b}}=H_{\mathrm{rms}} /\left(\beta \gamma_{\mathrm{b}}\right)$, we obtain

$S_{y}=\frac{\rho g}{16} \frac{H_{\mathrm{rms}}}{\beta \gamma_{\mathrm{b}}} \sin \theta \cos \theta$,

where $g$ is the gravitational acceleration $\left(g=9.81 \mathrm{~m} \mathrm{~s}^{-2}\right)$, $\gamma_{\mathrm{b}}$ is the breaking coefficient for irregular waves $\left(\gamma_{\mathrm{b}}=0.42\right.$, Thornton and Guza, 1983), $\beta$ is the beach slope $(\beta=0.015)$ and $\theta$ is the offshore wave angle (from the shore normal). $S_{y}$ is an approximation of the term $\partial S_{x y} / \partial y$ in the alongshore momentum balance equation, a term that is equivalent to $T_{y}$ in the same equation.

Figure 11a and b show the seasonal variability of $S_{y}$ and $T_{y}$ respectively. The comparison of both figures shows that both forcings are of the same order of magnitude and can therefore play a role in the bar dynamics, although $S_{y}$ is twice as large as $T_{y}$. Only the wind stress seasonal analysis shows more highly energetic conditions in winter 2009 than in winter 2010, in accordance with the results of the migration rate. However, the wind stress shows more highly energetic conditions in autumn than in winter, while the migration rate shows lower values in autumn 2009 than in winter 2009. The wave stress seasonal analysis shows lower differences between autumns and winters, with larger values still being in the autumn.

\subsection{Sediment transport}

The relationship between the bar migration and the alongshore component of the sediment transport is also investigated. We use a formulation based on the Soulsby and Van Rijn formula (Soulsby, 1997). This formulation has been used in modelling studies to explain the formation of different kinds of transverse bars (Ribas et al., 2012; Garnier et al., 2006). 
a)

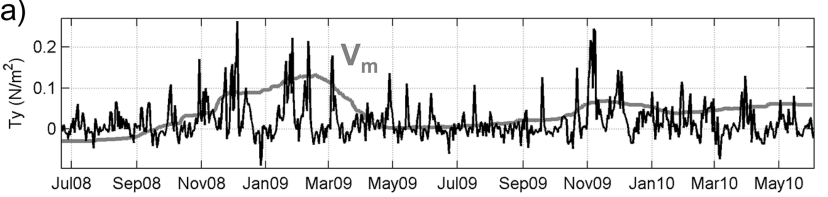

b)

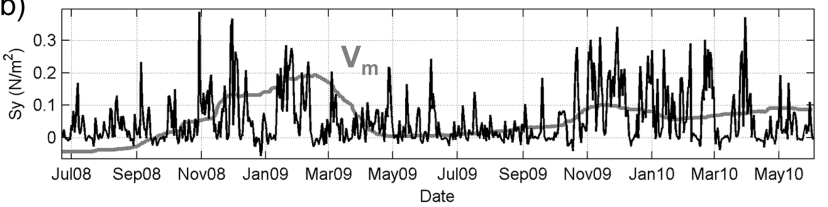

Figure 10. Time series of the daily averaged (a) alongshore wind stress $\left(T_{y}\right.$, black) and (b) alongshore wave stress ( $S_{y}$, black). The grey lines represent the behaviour of the bar migration rate $V_{\mathrm{m}}$ that has been rescaled with the above variables.

\subsubsection{Soulsby and Van Rijn formula}

Here, we assume that the general formulation of the alongshore component of the sediment transport is given by

$q=\alpha\left(V_{\text {wave }}+V_{\text {wind }}\right)$,

where $\alpha$ is the sediment stirring function, $V_{\text {wave }}$ is the alongshore component of the wave- and depth-averaged current driven by the wind waves, and $V_{\text {wind }}$ is the alongshore component of the depth-averaged current driven by the local wind.

The alongshore current generated by the wind waves is approximated from the formula presented by Komar and Inman (1970):

$V_{\text {wave }}=1.17\left(g H_{\mathrm{rms}}\right)^{0.5} \sin \theta_{\mathrm{b}} \cos \theta_{\mathrm{b}}$,

where $\theta_{\mathrm{b}}$ is the wave angle at breaking. By using Snell's law and the dispersion relationship, Eq. (5) has been evaluated at the breaking depth, defined as $H_{\mathrm{rms}} / \gamma_{\mathrm{b}}\left(\gamma_{\mathrm{b}}=0.42\right)$ from the incident wave angle computed with the SWAN model (Sect. 4.1).

The alongshore current generated by the wind is computed by assuming the alongshore momentum balance between the wind stress and the bottom friction in the case of a quadratic friction law:

$V_{\text {wind }}= \pm\left|\frac{T_{y}}{\rho c_{\mathrm{d}}}\right|^{0.5}$

where $c_{\mathrm{d}}$ is the hydrodynamic drag coefficient set as $c_{\mathrm{d}}=$ 0.005 .

The stirring function in Eq. (4) is approximated with the Soulsby and Van Rijn formula (Soulsby, 1997) as

$\alpha= \begin{cases}A_{\mathrm{S}}\left(U_{\text {eq }}-U_{\text {crit }}\right)^{2.4} & \text { if } U_{\text {eq }}>U_{\text {crit }} \\ 0 & \text { otherwise },\end{cases}$

where $A_{\mathrm{S}}$ is a coefficient that represents the suspended load and the bed load transport and $U_{\text {crit }}$ is the critical velocity
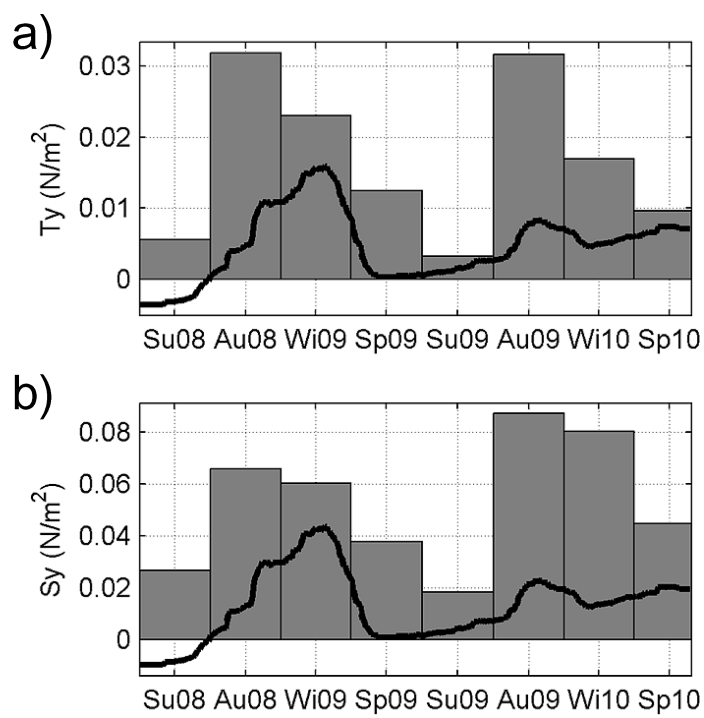

Figure 11. Seasonal variability of (a) alongshore wind stress $\left(T_{y}\right)$ and (b) alongshore wave stress $\left(S_{y}\right)$. The black lines represent the behaviour of the bar migration rate $V_{\mathrm{m}}$ that has been rescaled with the above variables. The bottom axes indicate the seasons, from summer 2008 to spring 2010.

above which the sediment can be transported. $A_{\mathrm{S}}$ and $U_{\text {crit }}$ depend essentially on the sediment characteristics and on the water depth (for more details see Soulsby, 1997; Garnier et al., 2006). The equivalent stirring velocity is defined as

$U_{\text {eq }}=\left(U_{\text {wind }}^{2}+V_{\text {wave }}^{2}+\frac{0.018}{C_{\mathrm{d}}} U_{\mathrm{b}}^{2}\right)^{0.5}$,

where $U_{\mathrm{b}}$ is the wave orbital velocity amplitude at the bottom (computed at wave breaking), $C_{\mathrm{d}}$ is the morphodynamic drag coefficient computed with the formula of Soulsby (1997) and $U_{\text {wind }}$ is the modulus of the current generated by the wind:

$U_{\text {wind }}=\left(\frac{C_{\mathrm{f}}}{c_{\mathrm{d}}} W^{2}\right)^{0.5}$.

\subsubsection{Tidal correction factor}

Although the tidal level variations have been included to compute the incoming wave time series, the sediment transport formula defined in Sect. 4.3.1 does not take into account that the bars can be emerged, and are therefore inactive, during part of a tidal cycle. If strong winds and high waves (despite the limited fetch) coincide with the time of emersion, they will have no effect and the effective sediment transport should be zero. Furthermore, the time of submersion depends on the tidal range. During neap tides the bar system is affected by the marine dynamics almost $100 \%$ of the time because the full emersion of the bars occurs only when the tide is at its lowest level (during a short time period). However, during spring tides, the active time period is reduced because 
the tide falls lower and the bars stay emerged for a longer time.

These effects have been quantified by means of a tidal correction factor $\left(\alpha_{\mathrm{t}}\right)$, ranging from 0 to 1 , which evaluates how exposed the bars are due to the stirring resulting from the hydrodynamics. The corrected transport formula is then computed as

$q^{\mathrm{t}}=\alpha_{\mathrm{t}} q$

$\alpha_{\mathrm{t}}$ varies every hour, depending on the surf-zone width $\left(X_{\mathrm{b}}\right)$ and on the tidal level $\left(\eta_{\mathrm{t}}\right)$. It is computed by using the following formula (see Fig. 12):

$\alpha_{\mathrm{t}}=\left\{\begin{array}{lll}0 & \text { if } & Z_{3}<\eta_{\mathrm{t}} \\ \frac{Z_{3}-\eta_{\mathrm{t}}}{Z_{3}-Z_{2}} \alpha_{\mathrm{t}, \text { max }} & \text { if } & Z_{2}<\eta_{\mathrm{t}}<Z_{3} \\ \alpha_{\mathrm{t}, \max } & \text { if } & Z_{1}<\eta_{\mathrm{t}}<Z_{2} \\ \frac{\eta_{\mathrm{t}}-Z_{0}}{Z_{1}-Z_{0}} \alpha_{\mathrm{t}, \max } & \text { if } & Z_{0}<\eta_{\mathrm{t}}<Z_{1} \\ 0 & \text { if } & \eta_{\mathrm{t}}<Z_{0},\end{array}\right.$

where $\alpha_{\mathrm{t}, \max }$ quantifies the ratio between the surf-zone width (corresponding to the $H_{\text {rms }}$ ) and the cross-shore span of the bars, representing the percentage of the bars that could be within the active surf zone,

$\alpha_{\mathrm{t}, \max }=\frac{X_{\mathrm{b}}}{L}=\frac{H_{\mathrm{rms}}}{\beta \gamma_{\mathrm{b}} L}$,

where $L$ is the mean cross-shore span of the bars $(L=$ $100 \mathrm{~m}$ ) and $X_{\mathrm{b}}$ is the width of the active surf zone (Fig. 12). $Z_{0}, Z_{1}, Z_{2}$ and $Z_{3}$ are defined as (see Fig. 12)

$$
\left\{\begin{array}{l}
Z_{0}=2.5 \mathrm{~m}=\text { level of the bar lower end } \\
Z_{1}(t)=Z_{0}+h^{*}(t)=2.5+\gamma_{\mathrm{b}}^{-1} H_{\mathrm{rms}}(t) \\
Z_{2}=3.7 \mathrm{~m}=\text { level of the bar upper end } \\
Z_{3}(t)=Z_{2}+h^{*}(t)=3.7+\gamma_{\mathrm{b}}^{-1} H_{\mathrm{rms}}(t) .
\end{array}\right.
$$

$Z_{0}$ and $Z_{2}$ (levels of the bar lower end and upper end) are constant and determined from the 3-D-geometry (Fig. 5). $Z_{1}$ and $Z_{3}$ depend on the active depth $h^{*}$ defined as $\left(h^{*}=\right.$ $\left.H_{\text {rms }} / \gamma_{\mathrm{b}}\right)$.

To better understand these formulas, let us consider a day with constant wave height. The tidal correction factor is maximum $\left(\alpha_{\mathrm{t}}=\alpha_{\mathrm{t}, \max }\right)$ when the maximum depth at the bars is larger than the active depth $\left(\eta_{\mathrm{t}} \geq Z_{1}\right)$ and when the sea level does not exceed the upper end of the bars $\left(\eta_{\mathrm{t}} \leq Z_{2}\right)$. This means that the complete surf-zone width is located over the bars. Furthermore, the sediment transport over the bars vanishes if the sea level does not reach the lower end of the bars $\left(\eta_{\mathrm{t}} \leq Z_{0}\right.$, i.e. too shallow) and if the minimum water depth at the bars is larger than the active depth $\left(\eta_{\mathrm{t}} \geq Z_{3}\right.$, i.e. too deep).

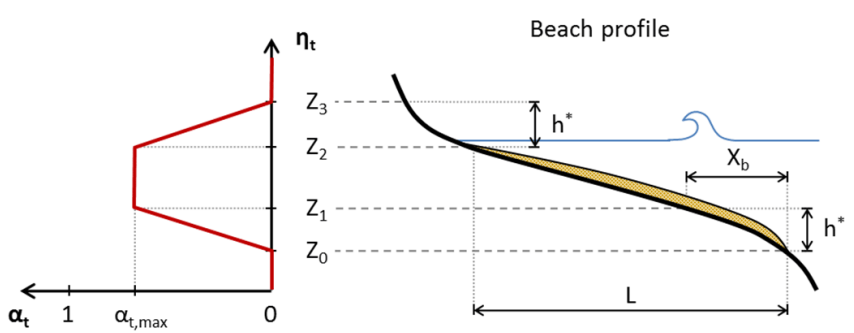

Figure 12. Parameters for the calculation of the tidal correction factor $\left(\alpha_{\mathrm{t}}\right)$, which depends on the tidal level $\left(\eta_{\mathrm{t}}\right)$; the mean crossshore span of the bars $(L)$; the active depth $\left(h^{*}\right)$; the surf-zone width $\left(X_{\mathrm{b}}\right)$; and the level of the bar lower end $\left(Z_{0}\right)$, the bar upper end $\left(Z_{2}\right)$ and the levels $Z_{1}$ and $Z_{3}$, which vary with the wave height $\left(H_{\mathrm{rms}}\right)$.

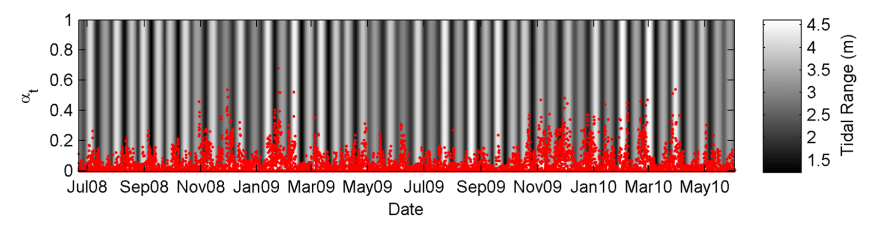

Figure 13. Time series of: the tidal correction factor $\alpha_{\mathrm{t}}$ (red dots); and the tidal range (greyscale, vertical bars).

From our observations, the tidal factor never reaches 1 (Fig. 13). $\alpha_{\mathrm{t}}=1$ could occur for strong stormy conditions if the surf-zone width is as large as the bar width $\mathrm{L}\left(H_{\mathrm{rms}}>\right.$ $0.5)$, and if it coincides with high tide $\left(\eta_{\mathrm{t}}=Z_{2}\right)$. Figure 13 shows that $\alpha_{\mathrm{t}}$ reaches its maximum values during neap tides, as was expected, generally as the tidal level is close to $Z_{2}$ a larger part of the day. During spring tides, the time during which the tidal level is between $Z_{3}$ and $Z_{0}$ is highly reduced. Consequently, the tidal factor is generally minimum.

\subsubsection{Results}

In order to analyse the correlation between $q$ and the bar migration rate $V_{\mathrm{m}}$, the time-dependent sediment transport rate must be computed. First, we integrate the sediment transport over the time intervals $T_{k}$, for each segment that characterises the bar movement (as explained in Sect. 3.2.2), and then we apply an equation equivalent to Eq. (1) for that sediment transport data. The obtained time series of the timedependent sediment transport is shown in Fig. 14.

Figure 14a, which displays the sediment transport without the tidal correction, shows that the sediment transport is weaker in spring 2009 than in spring 2010, corresponding to a smaller migration rate. However, the seasonal average of $q$ shows similar values for autumn-winter 2009 and autumnwinter 2010, while the migration rate results show lower values during 2010 . The correlation coefficient obtained is $r=0.75$.

The addition of the tidal factor improves the results (Fig. 14b) increasing the correlation coefficient to $r=0.8$. All correlations obtained are highly significant $(p<0.001)$. 
a)

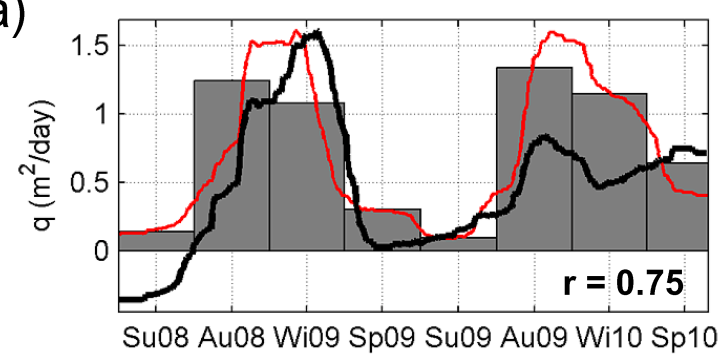

b)

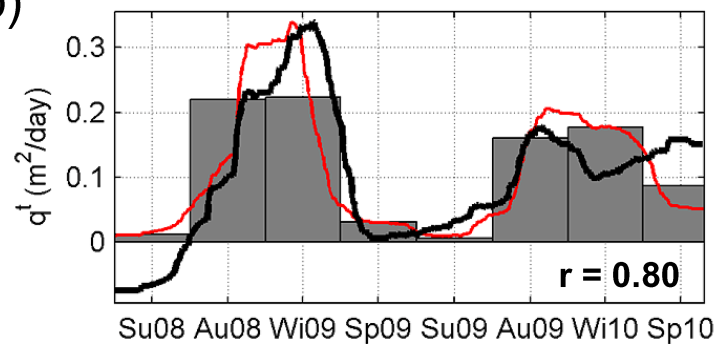

Figure 14. Sediment transport evaluation. Analysis of (a) alongshore component of sediment transport $q$ (without tidal correction), and (b) $q^{\mathrm{t}}$ (with tidal correction). The grey areas show the seasonally averaged transport and the red lines show the time-dependent sediment transport time series (obtained by averaging over the $T_{k}$ intervals). The black lines represent the behaviour of the bar migration rate $V_{\mathrm{m}}$ that has been rescaled with the above variables. The correlation coefficient of both lines is shown in the bottom right corner. The bottom axes indicate the seasons, from summer 2008 to spring 2010.

The seasonal analysis shows higher values of sediment transport during autumn-winter 2009 than autumn-winter 2010, corresponding with higher time-dependent migration rates during autumn-winter 2009. Again, the sediment transport computed in spring 2009 is lower than in spring 2010, corresponding well with the smaller migration rates measured in spring 2009. The time-dependent sediment transport time series of $q^{\mathrm{t}}$ (Fig. 14b) follows the main shape of the measured time-dependent migration rate. The bigger differences are found at the beginning and end of the study period, where the time-dependent migration rates are less reliable, as explained in Sect. 3.2.2. In particular, none of the formulas used managed to predict the negative (westward) migration reported during summer 2008, but, as previously mentioned, these negative migration rates may be not realistic.

Figure 9e shows the flow rate of Miera River. This flow rate is greater during winter 2009 than winter 2010, so the faster migration rate of the bars during this period could be influenced by the river discharge, possibly because it is a source of sediment. However, tests performed by including additional sediment stirring due to the river flow do not show improvement in the results.

\section{Conclusions}

A small-scale finger bar system has been identified on the intertidal zone of the swell-protected beach of El Puntal Spit in the Bay of Santander (northern coast of Spain). The beach is characterised by a constant slope of 0.015 and by uniform sand with $D_{50}=0.27 \mathrm{~mm}$. This system appears on the flat intertidal region, which extends over $600 \mathrm{~m}$ on the alongshore direction and between 70 and $130 \mathrm{~m}$ on the cross-shore direction (the cross-shore span is determined by the tidal horizontal excursion).

A system of 15 bars was observed by using the Horus video imaging system during 2 years (between 23 June 2008 and 2 June 2010). The bar system has been digitised from daily images at low tide. The data set is almost continuous, with good quality data $81 \%$ of the time and a maximum continuous period of time without data of no more than 6 days.

The geometric characteristics of the system are almost constant in time. The mean wavelength of the bar system is $26 \mathrm{~m}$ and the bar amplitude is between 10 and $20 \mathrm{~cm}$. Moreover, the bars have an oblique orientation with respect to the low-tide shoreline, with a mean angle of $26^{\circ}$ to the east from the shore normal. We noticed differences in the geometry along the domain: the western bars (first half) are more irregular and have smaller wavelength than the eastern bars (second half).

The full system slowly migrates to the east (against the ebb flow) with a mean speed of $6 \mathrm{~cm} \mathrm{day}^{-1}$ that varies between bars. In general, larger wavelength bars migrate more slowly, in agreement with previous studies (Garnier et al., 2006). An episode of merging of two bars was observed on 28 March 2009: the bar with the smallest wavelength is faster and merges with the next bar. Bars form on the western end of the system, migrate east and then decay at the eastern end.

A detailed analysis of the bar motion, from a piecewise regression of the bar positions, has shown that bars migrate more quickly in winter than in summer, with maximum migration rates obtained in winter $2009\left(0.15 \mathrm{~m} \mathrm{day}^{-1}\right)$. Some negative speeds (migration to the west) have been computed (during summer 2008), but this result could be an effect of the limitations of the piecewise regression at the beginning and end of the time series.

The primary forcing mechanism that is acting on the bar dynamics is the wind over the water surface. Offshore of the bar system, the mean (annual) flow is ebb-oriented (to the west), because of the Miera River discharge and the astronomical tide. However, in the intertidal zone their effects on the mean flow vanish. There, wind shear stress and wind waves generated over a fetch of up to $4.5 \mathrm{~km}$ at high tide seem to determine the direction of the alongshore transport.

Although the residual tidal current is weak, the tide seems to be important in the bar dynamics as the tidal range changes the mean (daily) fetch as well as the time of exposure of the bars to the marine dynamics. Furthermore, the river discharge 
could act as input of suspended sediment in the bar system and play a role in the bar dynamics.

The correlation between the bar migration and the alongshore component of the sediment transport has been analysed by using the Soulsby and Van Rijn formulation. The inclusion of a tidal correction factor, simulating that the active time depends on the tidal level and the wave height, improves the results.

Finally, the bar system is persistent and neither formation nor destruction events of the entire system have been observed. Further studies are necessary to understand the formation processes and the full dynamics of these small-scale finger bars. In situ measurements of the hydrodynamics and sediment concentrations, as well as numerical morphological modelling, are essential in order to deepen our understanding. The bar system here has an oblique down-current orientation with respect to the migration direction and has similar characteristics and dynamics to the system described by previous theoretical (modelling) studies that consider the forcing due to waves only (e.g. Garnier et al., 2006). However, in our estuarine environment, the dynamics are more complex as the actions of different forcings are of the same order of magnitude.

Acknowledgements. The authors thank Puertos del Estado (Spanish Government) for providing tide-gauge data. The work of R. Garnier is supported by the Spanish Government through the "Juan de la Cierva" programme. This research is part of the ANIMO (BIA2012-36822) project, which is funded by the Spanish Government. The authors thank the editor, G. Coco, and the referees, F. Ribas and E. Gallagher, for their useful comments.

Edited by: G. Coco

\section{References}

Bárcena, J. F., García, A., García, J., Álvarez, C., and Revilla, J. A.: Surface analysis of free surface and velocity to changes in river flow and tidal amplitude on a shallow mesotidal estuary: an application in Suances Estuary (Nothern Spain), J. Hydrol., 14, 301318, 2012.

Bidegain, G., Bárcena, J. F., García, A., and Juanes, J. A.: LARVAHS: predicting clam larval dispersal and recruitment using habitat suitability-based particle tracking mode, Ecol. Model., 268, 78-92, 2013.

Booij, N., Ris, R. C., and Holthuijsen, L. H.: A third-generation wave model for coastal regions, Part I, Model description and validation, J. Geophys. Res., 104, 7649-7666, 1999.

Bruner, K. R. and Smosna, R. A.: The movement and stabilization of beach sand on transverse bars, Assateague Island, Virginia, J. Coastal Res., 5, 593-601, 1989.

Camus, P., Méndez, F. J., and Medina, R.: A hybrid efficient method to downscale wave climate to coastal areas, Coast. Eng., 58, 851$862,2011$.
Castelle, B., Bonneton, P., Dupuis, H., and Senechal, N.: Double bar beach dynamics on the high-energy meso-macrotidal French Aquitanian coast: a review, Mar. Geol., 245, 141-159, 2007.

Dean, R. G. and Dalrymple, R. A.: Water wave mechanics for engineers and scientists, World Scientific, 157-158, 1991.

Falqués, A.: Formación de topografía rítmica en el Delta del Ebro, Revista de Geofísica, 45, 143-156, 1989 (in Spanish).

Galal, E. M. and Takewaka, S.: Longshore migration of shoreline mega-cusps observed with x-band radar, Coast. Eng. J., 50, 247276, 2008.

Garnier, R., Calvete, D., Falqués, A., and Caballeria, M.: Generation and nonlinear evolution of shore-oblique/transverse sand bars, J. Fluid Mech., 567, 327-360, 2006.

Garnier, R., Calvete, D., Falqués, A., and Dodd, N.: Modelling the formation and the long-term behavior of rip channel systems from the deformation of a longshore bar, J. Geophys. Res., 113, C07053, doi:10.1029/2007JC004632, 2008.

Garnier, R., Medina, R., Pellón, E., Falqués, A., and Turki, I.: Intertidal finger bars at El Puntal spit, bay of Santander, Spain, in: Proceedings of the 33rd Conference on Coastal Engineering, ASCE, Santander, Spain, 1-8, 2012.

Gelfenbaum, G. and Brooks, G. R.: The morphology and migration of transverse bars off the west-central Florida coast, Mar. Geol., 200, 273-289, 2003.

Goodfellow, B. W. and Stephenson, W. J.: Beach morphodynamics in a strong-wind bay: a low-energy environment?, Mar. Geol., 214, 101-116, 2005.

Green, M. O., Black, K. P., and Amos, C. L.: Control of estuarine sediment dynamics by interactions between currents and waves at several scales, Mar. Geol., 144, 97-116, 1997.

Gutiérrez, O., González, M., and Medina, R.: A methodology to study beach morphodynamics based on self-organizing maps and digital images, in: Proceedings of the Coastal Sediments 2011, World Scientific, 2453-2464, 2011.

Holman, R. A., Sallenger Jr., A. H., Lippmann, T. C. D., and Haines, J. W.: The application of video image processing to the study of nearshore processes, Oceanography, 6, 78-85, 1993.

Komar, P. and Inman, D.: Longshore sand transport on beaches, J. Geophys. Res., 75, 5514-5527, 1970.

Konicki, K. M. and Holman, R. A.: The statistics and kinematics of transverse sand bars on an open coast, Mar. Geol., 169, 69-101, 2000.

Kroon, A., Davidson, M. A., Aarninkhof, S. G. J., Archetti, R., Armaroli, C., González, M., Medri, S., Osorio, A., Aagaard, T., Holman, R. A., and Spanhoff, R.: Application of remote sensing video systems to coastline management problems, Coast. Eng., 54, 493-505, 2007.

Lafon, V., Dupuis, H., Howa, H., and Froidefond, J. M.: Determining ridge and runnel longshore migration rate using spot imagery, Oceanol. Acta, 25, 149-158, 2002.

Levoy, F., Anthony, E. J., Monfort, O., Robin, N., and Bretel, P.: Formation and migration of transverse bars along a tidal sandy coast deduced from multi-temporal Lidar datasets, Mar. Geol., 342, 39-52, 2013.

Longuet-Higgins, M. S. and Stewart, R. W.: Radiation stresses in water waves: a physical discussion with applications, Deep-Sea Res., 11, 529-562, 1964. 
Losada, M. A., Medina, R., Vidal, C., and Roldan, A.: Historical evolution and morphological analysis of "EI Puntal" Spit, Santander (Spain), J. Coastal Res., 7, 711-722, 1991.

Losada, M. A., Medina, R., Vidal, C., and Losada, I. J.: Temporal and spatial cross-shore distributions of sediment at "El Puntal" spit, Santander, Spain, Coast. Eng., 1992, Proceedings of the Twenty-Third International Conference, 2251-2264, 1992.

Medellín, G., Medina, R., Falqués, A., and González, M.: Coastline sand waves on a low-energy beach at "El Puntal" spit, Spain, Mar. Geol., 250, 143-156, 2008.

Medellín, G., Falqués, A., Medina, R., and González, M.: Coastline sand waves on a low-energy beach at El Puntal spit, Spain: linear stability analysis, J. Geophys. Res., 114, C03022, doi:10.1029/2007JC004426, 2009.

Medina, R., Marino-Tapia, I., Osorio, A., Davidson, M., and Martín, F. L.: Management of dynamic navigational channels using video techniques, Coast. Eng., 54, 523-537, 2007.

Menéndez, M., Tomás, A., Camus, P., García-Díez, M., Fita, L., Fernández, J., Méndez, F. J., and Losada, I. J.: A methodology to evaluate regional-scale offshore wind energy resources, OCEANS'11 IEEE Santander Conference, Spain, 1-9, 2011.

Niedoroda, A. W. and Tanner, W. F.: Preliminary study of transverse bars, Mar. Geol., 9, 41-62, 1970.

Nordstrom, K. F. and Jackson, N. L.: Physical processes and landforms on beaches in short fetch environments in estuaries, small lakes and reservoirs: a review, Earth-Sci. Rev., 111, 232-247, 2012.

Price, T. D. and Ruessink, B. G.: State dynamics of a double sandbar system, Cont. Shelf. Res., 31, 659-674, 2011.

Ranasinghe, R., Symonds, G., Black, K., and Holman, R.: Morphodynamics of intermediate beaches: a video imaging and numerical modelling study, Coast. Eng., 51, 629-655, 2004.
Requejo, S., Medina, R., and González, M.: Development of a medium-long term beach evolution model, Coast. Eng., 55, 1074-1088, 2008.

Ribas, F. and Kroon, A.: Characteristics and dynamics of surfzone transverse finger bars, J. Geophys. Res., 112, F03028, doi:10.1029/2006JF000685, 2007.

Ribas, F., Falqués, A., and Montoto, A.: Nearshore oblique sand bars, J. Geophys. Res., 108, C43119, doi:10.1029/2001JC000985, 2003.

Ribas, F., de Swart, H. E., Calvete, D., and Falqués, A.: Modeling and analyzing observed transverse sand bars in the surf zone, J. Geophys. Res., 117, F02013, doi:10.1029/2011JF002158, 2012.

Ribas, F., ten Doeschate, A., de Swart, H., Ruessink, G., and Calvete, D.: Observations and modelling of surf-zone transverse finger bars at the Gold Coast, Australia, Ocean Dynam., doi:10.1007/s10236-014-0719-4, in press, 2014.

Soulsby, R. L.: Dynamics of Marine Sands, Thomas Telford, London, UK, 1997.

Thornton, B. and Guza, R. T.: Transformation of wave height distribution, J. Geophys. Res., 88, 5925-5938, 1983.

Thornton, E. B., MacMahan, J., and Sallenger Jr., A. H.: Rip currents, mega-cusps, and eroding dunes, Mar. Geol., 240, 151-167, 2007.

van Enckevort, I. M. J., Ruessink, B. G., Coco, G., Suzuki, K., Turner, I. L., Plant, N. G., and Holman, R. A.: Observations of nearshore crescentic sandbars, J. Geophys. Res., 109, C06028, doi:10.1029/2003JC002214, 2004.

Wijnberg, K. M. and Kroon, A.: Barred beaches, Geomorphology, 48, 103-120, 2002.

Wright, L. D. and Short, A. D.: Morphodynamic variability of surf zones and beaches: a synthesis, Mar. Geol., 56, 93-118, 1984. 